\title{
The effect of nephrectomy on Klotho, FGF-23 and bone metabolism
}

\author{
Katarzyna Kakareko $^{1}$ - Alicja Rydzewska-Rosolowska ${ }^{1}$ - Szymon Brzosko ${ }^{1}$ • \\ Joanna Gozdzikiewicz-Lapinska ${ }^{2}$ - Ewa Koc-Zorawska ${ }^{2}$ Pawel Samocik ${ }^{3}$. \\ Robert Kozlowski $^{3} \cdot$ Michal Mysliwiec $^{1} \cdot$ Beata Naumnik $^{1} \cdot$ Tomasz Hryszko $^{1}$
}

Received: 19 July 2016 / Accepted: 17 January 2017 / Published online: 27 January 2017

(c) The Author(s) 2017. This article is published with open access at Springerlink.com

\begin{abstract}
Background Increased concentration of fibroblast growth factor 23 (FGF-23) and decreased levels of soluble Klotho (sKL) are linked to negative clinical outcomes among patients with chronic kidney disease and acute kidney injury. Therefore, it is reasonable to hypothesize that GFR reduction caused by nephrectomy might alter mineral metabolism and induces adverse consequences. Whether nephrectomy due to urological indications causes derangements in FGF-23 and sKL has not been studied. The aim of the study was to evaluate the effect of acute GFR decline due to unilateral nephrectomy on bone metabolism, FGF23 and sKL levels.

Methods This is a prospective, single-centre observational study of patients undergoing nephrectomy due to urological indications. Levels of C-terminal FGF-23 (c-FGF-23), sKL and bone turnover markers [ $\beta$-crosslaps (CTX), bonespecific alkaline phosphatase (bALP) and tartrate-resistant acid phosphatase $5 b$ (TRAP 5b)] were measured before and after surgery ( $5 \pm 2$ days).

Results Twenty-nine patients were studied (14 females, age $63.0 \pm 11.6$, eGFR $\left.87.3 \pm 19.2 \mathrm{ml} / \mathrm{min} / 1.73 \mathrm{~m}^{2}\right)$. After surgery, eGFR significantly declined $(p<0.0001)$. Nephrectomy significantly decreased sKL level [709.8
\end{abstract}

Katarzyna Kakareko

kponikwicka@o2.pl

1 I Department of Nephrology and Transplantation with Dialysis Unit, Medical University of Bialystok, Ul. Zurawia 14, 15-540 Białystok, Poland

2 II Department of Nephrology and Hypertension with Dialysis Unit, Medical University of Bialystok, Białystok, Poland

3 Department of Oncological and General Urology, J. Sniadecki Provincial Hospital, Białystok, Poland
(599.9-831.2) vs. $583.0(411.7-752.6) \mathrm{pg} / \mathrm{ml}, p<0.001]$ and did not change c-FGF-23 concentration [70.5 (49.8$103.3)$ vs. $77.1(60.5-109.1) \mathrm{RU} / \mathrm{ml}, p=0.9]$. Simultaneously, alterations in bone turnover markers were observed. Serum concentration of CTX increased [0.49 (0.4-0.64) vs. $0.59(0.46-0.85) \mathrm{ng} / \mathrm{ml}, p=0.001]$, while bALP and TRAP 5b decreased [23.6 (18.8-31.4) vs. 17.9 (15.0-22.0) $\mathrm{U} / 1, p<0.0001$ and $3.3(3.0-3.7)$ vs. $2.8(2.3-3.2) \mathrm{U} / 1$, $p<0.001$, respectively].

Conclusions Nephrectomy among patients with preserved renal function before surgery does not increase c-FGF23 but reduces sKL. Moreover, nephrectomy results in derangements in bone turnover markers in short-term follow-up. These changes may participate in pathogenesis of bone disease after nephrectomy.

Keywords Acute GFR decline · Nephrectomy · Klotho · FGF-23 · Bone metabolism

\section{Introduction}

Fibroblast growth factor 23 (FGF-23) and Klotho are key players in maintaining mineral homoeostasis. Increase in FGF-23 concentration is accompanied by Klotho reduction as chronic kidney disease (CKD) worsens $[1,2]$. Both molecules have gained attention for their association with important clinical outcomes such as cardiovascular incidents [3] and mortality [4]. It has been thought that FGF-23 and Klotho may link bone mineral disturbances with cardiovascular mortality.

Recently, it was shown that among patients with acute kidney injury (AKI), FGF-23 concentrations are elevated and associated with negative clinical outcomes $[5,6]$. In contrast, there is little data on FGF-23 and soluble Klotho 
(sKL) after mild-to-moderate reduction in glomerular filtration rate (GFR), which is evoked by nephrectomy. This might be especially important with regard to living kidney donation and patients undergoing nephrectomy due to urological indications in light of negative connotations between FGF-23 and clinical consequences.

It is a matter of debate whether and how acute GFR decline predisposes to bone metabolism disturbances. The impact of those changes on bone metabolism has been studied in two groups of patients: living kidney donors and patients undergoing nephrectomy. On the one hand, nephrectomy due to renal cell carcinoma is a significant risk for osteoporosis and increased fracture risk [7], but, on the other hand, data concerning living kidney donors are conflicting. It is reported that even though living kidney donors experience alterations of hormones involved in bone metabolism [8-10], there is no increased fracture risk [11]. The precise mechanism by which acute GFR decline predisposes to bone metabolism disturbances is largely unknown.

A nephrectomy due to urological indications in patients with preserved renal function offers unique clinical model to study effect of acute mild-to-moderate GFR decline, as the patients serve as their own controls without any confounding factors always present among patients with CKD and even more pronounced in AKI setting.

Regarding the fact that alterations in FGF-23 and sKL disturb bone health early in the course of CKD, the study was undertaken to evaluate the effect of acute GFR decline due to unilateral nephrectomy on bone metabolism, FGF-23 and sKL levels. The secondary aim was to assess whether changes in the concentration of the above molecules evoked by nephrectomy are associated with alterations in the markers of bone formation and/or resorption.

\section{Materials and methods}

\section{Study design}

This study is a post hoc analysis of frozen blood and urine samples from the previously reported data [12]. The former study was designed as a prospective, single-centre trial and patient served as a self-control group. All patients undergoing nephrectomy due to urological indications in the Department of Oncological and General Urology, Sniadecki Provincial Hospital in Bialystok (Poland), were enrolled unless end-stage renal disease requiring dialysis (four patients) or lack of informed consent (five patients) was present.

After the surgery, all the patients underwent standard hydration protocol with isotonic saline. During the first $24 \mathrm{~h}, 2500 \mathrm{ml}$ of intravenous fluid was administered and nil per os was prescribed; on the second day, $1000 \mathrm{ml}$ of intravenous fluid was given and patients were allowed to start progressive fluid oral intake. From the third day, no intravenous fluids were given.

The study was approved by the local ethics committee. The protocol adhered to the principles of the Declaration of Helsinki and written informed consent was obtained from each participant.

\section{Laboratory measurements}

Urine and venous fasting blood samples were collected on the morning prior to surgery and after nephrectomy ( $5 \pm 2$ days after nephrectomy depending on the duration of hospitalization). To prevent possible changes due to intra-day variability, our samples were collected always at early morning, after overnight fasting. Plasma, serum and urine were centrifuged, aliquoted and frozen at $-70{ }^{\circ} \mathrm{C}$ until assayed.

Serum soluble Klotho and plasma C-terminal FGF-23 (c-FGF-23) levels were measured using the enzyme-linked immunosorbent assay (ELISA) kit (IBL, International $\mathrm{GmbH}$, Hamburg, Germany; intra-assay $\mathrm{CV}<4 \%$ and Immutopics, Inc., San Clemente, CA, USA; intra-assay $\mathrm{CV}<2.5 \%$, respectively). Serum bone-specific alkaline phosphatase (bALP) was determined by an ELISA kit from MicroVue (Quidel Corporation, San Diego, CA, USA; intra-assay $\mathrm{CV}<6 \%$ ). Tartrate-resistant acid phosphatase 5b (TRAP 5b) was measured in serum by an ELISA kit from MicroVue (Quidel Corporation, San Diego, CA, USA; intra-assay CV $<2.2 \%$ ). ELISA immunoassay was used to measure serum cross-linked C-telopeptide of type 1 collagen (CTX, CrossLaps, IDS Nordic A/S, Herlev, Denmark; intra-assay CV < 6\%). Plasma intact PTH levels were measured using Immutopics assay (Inc., San Clemente, CA, USA). All samples were assayed according to manufacturer's recommendations. For sKL, samples were diluted two times. Blood and urine levels of creatinine, calcium and phosphate were determined with standard laboratory methods.

\section{Calculations and statistics}

To estimate phosphate and calcium renal handling, we used the ratio of tubular maximum reabsorption to the glomerular filtration rate $\left(\mathrm{TmPO}_{4} / \mathrm{eGFR}\right.$ - as an index for the phosphate renal threshold) and urinary fractional excretion of calcium $\left(\mathrm{FE}_{\mathrm{Ca}}\right)$. The calculations were made as follows:

$\mathrm{TmPO}_{4} / \mathrm{eGFR}=\mathrm{PO}_{4} *\left(1-\mathrm{Fe}_{\mathrm{PO} 4}\right)$ if $\mathrm{Fe}_{\mathrm{PO} 4} \geq 0.2$ otherwise $\mathrm{TmPO}_{4} / \mathrm{eGFR}=\mathrm{PO}_{4} * \mathrm{e}\left(10.318 * \mathrm{Fe}_{\mathrm{PO} 4}^{2}-5.1\right.$ $\left.8 * \mathrm{Fe}_{\mathrm{PO} 4}+0.4\right)$, where urinary fractional excretion of phosphate $\left(\mathrm{Fe}_{\mathrm{PO} 4}\right)$ was computed as below: 
$\mathrm{Fe}_{\mathrm{PO} 4}=[($ urinary phosphate $\times$ serum creatinine $) /($ serum phosphate $\times$ urinary creatinine)] [13, 14],

and $\mathrm{FE}_{\mathrm{Ca}}=[($ urinary calcium $\times$ serum creatinine $) /$ (serum calcium $\times$ urinary creatinine) $] \times 100 \%$.

GFR was estimated using CKD epidemiology collaboration (CKD-EPI) equation [15].

Variable distribution was tested with the Shapiro-Wilk W test of normality. The normally distributed data were presented as mean $\pm 1 \mathrm{SD}$, the skewed data as median (interquartile range; IQR). Before statistical computations, logarithmic transformations were performed on skewed variables to obtain normal distribution, if possible. Student's $t$ test for paired samples or Wilcoxon signed-rank test was used to compare continuous variables at selected time points. Changes in measured parameters were expressed as delta $(\Delta)$ and calculated as follows: postoperative minus preoperative value. Associations between deltas were assessed using bivariate correlations with Pearson or Spearman's test depending on meeting the assumptions. Mixed regression analyses accounting for time effect were performed in search for longitudinal associations between variables of interest. Results were reported as beta coefficient $\beta$ and 95\% confidence intervals $(95 \% \mathrm{CI})$. A two-tailed $p$ value of $<0.05$ was considered statistically significant. All computations were performed with Statistica 12 (StatSoft, Tulsa, OK, USA).

\section{Results}

\section{Characteristics of the study population}

We enrolled twenty-nine patients (14 females) who underwent nephrectomy. The mean baseline eGFR was $87.3 \pm 19.2 \mathrm{ml} / \mathrm{min} / 1.73 \mathrm{~m}^{2}$. Additional baseline characteristics of the studied population are detailed in Table 1 . After nephrectomy in four subjects anuria occurred, thus parameters evaluated in urine were measured in 25 subjects. In these patients, hydration protocol was violated, as they received fluids according to their condition. Statistical computations were repeated after exclusion of these cases and yielded similar results. None of the patients required dialysis during the study duration.

Groups with partial and radical nephrectomy and with tumour and non-tumour did not differ significantly concerning evaluated parameters except from non-significant difference in baseline value of sKL between tumour and non-tumour group (tumour group-680.2 \pm 131.2 vs. nontumour group $-805.3 \pm 185.9, p=0.05$ ).

\section{Effect of nephrectomy on calcium, phosphate and iPTH}

Biochemical parameters before and after nephrectomy are presented in Table 2. As expected, eGFR declined
Table 1 Baseline characteristics of the study population

\begin{tabular}{ll}
\hline Characteristic & Value \\
\hline Age (years) & $63.0 \pm 11.6$ \\
Sex & \\
Male & $15(52 \%)$ \\
Female & $14(48 \%)$ \\
Nephrectomy & \\
Partial & $8(28 \%)$ \\
Radical & $21(72 \%)$ \\
Indication for nephrectomy & \\
Tumour & $21(72 \%)$ \\
Cirrhotic kidney & $4(14 \%)$ \\
Complex renal cysts & $2(7 \%)$ \\
Kidney stones & $1(3.5 \%)$ \\
Pyonephrosis & $1(3.5 \%)$ \\
eGFR, ml/min/1.73 $\mathrm{m}^{2}$ & $87.3 \pm 19.2$ \\
\hline
\end{tabular}

Data are mean $\pm \mathrm{SD}$ or number (percentage)

significantly after surgery compared with the baseline values $\left(87.3 \pm 19.2\right.$ vs. $69.8 \pm 24.7 \mathrm{ml} / \mathrm{min} / 1.73 \mathrm{~m}^{2}$, $p<0.0001)$. We observed significant decline in serum calcium and phosphate concentration $(p<0.0001$ and $p=0.002$, respectively), while urinary calcium $(p=0.02)$ and phosphate excretion (reduction in $\mathrm{TmPO}_{4} /$ eGFR, $p=0.001)$ increased. There was no significant change in intact PTH concentration during the study period.

Phosphatemia changes $[\Delta \mathrm{P}=-0.54(-1.01$ to 0.11$)$ $\mathrm{mmol} / \mathrm{l}]$ were positively associated with $\Delta \mathrm{iPTH}[\Delta=0.21$ ( -0.44 to 0.92$) \mathrm{pmol} / \mathrm{l} ; r=0.6, p=0.002]$ and $\Delta \mathrm{c}-\mathrm{FGF}-23$ [ $\Delta=3.0(-15.49$ to 26.29$) \mathrm{RU} / \mathrm{ml} ; r=0.6, p=0.0001]$. Phosphate level was determined by c-FGF-23 $[\beta=1.68$ (95\% CI 0.82-2.53), $p<0.001]$, iPTH [ $\beta=0.41$ (95\% CI $0.08-0.74), p=0.016]$ in mixed regression analysis model after adjustment for time effect and kidney function.

Alterations in serum calcium evoked by nephrectomy $(\Delta \mathrm{Ca}=-0.15 \pm 0.15 \mathrm{mmol} / \mathrm{l})$ were associated negatively with iPTH alterations $(\triangle \mathrm{iPTH})(r=-0.4, p=0.03)$ but not with any evaluated parameters. Serum calcium level was associated only with iPTH $[\beta=-0.44(95 \% \mathrm{CI}-0.78$ to $(-0.10)), p=0.013$ ] in mixed model adjusted for time effect and renal function.

\section{Effect of nephrectomy on c-FGF-23, sKL}

There was a significant decrease in sKL level $(p<0.0001)$ after nephrectomy (Fig. 1a). Serum concentration of c-FGF-23 was not changed by the procedure (Fig. 1b).

Alterations of c-FGF-23 concentration $(\Delta \mathrm{c}-\mathrm{FGF}-23)$ were associated with $\Delta \mathrm{P}(r=0.6, p=0.0001)$ and $\Delta \mathrm{eGFR}$ $\left(\Delta=-17.45 \pm 19.62 \mathrm{ml} / \mathrm{ml} / 1.73 \mathrm{~m}^{2} ; r=-0.4, p=0.04\right)$. 
Table 2 Changes in biochemical parameters after nephrectomy

\begin{tabular}{|c|c|c|c|}
\hline Parameter & Baseline & $\begin{array}{l}\text { After nephrec- } \\
\text { tomy }\end{array}$ & $p$ value \\
\hline $\begin{array}{l}\mathrm{eGFR}(\mathrm{ml} / \\
\left.\mathrm{min} / 1.73 \mathrm{~m}^{2}\right)\end{array}$ & $87.3 \pm 19.2$ & $69.8 \pm 24.7$ & $p<0.001$ \\
\hline $\begin{array}{l}\text { Creatinine (mg/ } \\
\mathrm{dl})^{\mathrm{a}}\end{array}$ & $0.82(0.56-1.7)$ & $1.02(0.58-6.28)$ & $p<0.001$ \\
\hline Calcium (mmol/l) & $2.31 \pm 0.11$ & $2.17 \pm 0.15$ & $p<0.001$ \\
\hline $\begin{array}{r}\text { Phosphate } \\
(\mathrm{mmol} / \mathrm{l})\end{array}$ & $1.14 \pm 0.2$ & $0.97 \pm 0.24$ & $p=0.002$ \\
\hline iPTH (pmol/l) & $3.12(2.02-3.66)$ & $2.68(2.04-4.51)$ & $p=0.6$ \\
\hline $\begin{array}{l}\text { Soluble Klotho } \\
\text { (pg/ml) }\end{array}$ & $\begin{array}{l}709.8(599.9- \\
831.2)\end{array}$ & $\begin{array}{l}583.0(411.7- \\
752.6)\end{array}$ & $p<0.001$ \\
\hline $\begin{array}{l}\mathrm{c}-\mathrm{FGF}-23 \text { (RU/ } \\
\mathrm{ml})\end{array}$ & $70.5(49.8-103.3)$ & $77.1(60.5-109.1)$ & $p=0.9$ \\
\hline CTX (ng/ml) & $0.49(0.4-0.64)$ & $0.59(0.46-0.85)$ & $p=0.001$ \\
\hline bALP (U/l) & $23.6(18.8-31.4)$ & $17.9(15.0-22.0)$ & $p<0.001$ \\
\hline TRAP 5b (U/l) & $3.3(3.0-3.7)$ & $2.8(2.3-3.2)$ & $p<0.001$ \\
\hline $\mathrm{FE}_{\mathrm{Ca}}(\%)$ & $0.67(0.33-0.85)$ & $1.14(0.59-1.38)$ & $p=0.02$ \\
\hline $\begin{array}{c}\mathrm{TmPO}_{4} / \mathrm{eGFR} \\
(\mathrm{mmol} / \mathrm{l})\end{array}$ & $1.07(0.84-1.35)$ & $0.8(0.64-0.93)$ & $p=0.001$ \\
\hline
\end{tabular}

Data are presented as number (percentage), mean \pm SD or median (interquartile range)

$e G F R$ estimated glomerular filtration rate, $i P T H$ intact parathyroid hormone, $c-F G F-23$ c-terminal fibroblast growth factor 23, CTX cross-linked C-telopeptide of type 1 collagen, $b A L P$ bone-specific alkaline phosphatase, TRAP $5 b$ tartrate-resistant acid phosphatase $5 \mathrm{~b}$, $F E_{C a}$ urinary fractional excretion of calcium, $\mathrm{TmPO}_{4} / \mathrm{eGFR}$ ratio of tubular maximum reabsorption rate to the glomerular filtration rate

${ }^{a}$ For creatinine, data are presented as the median (min-max)

Mixed regression analyses adjusted for time effect, renal function, and iPTH showed phosphate $[\beta=0.24$ (95\% CI $0.12-0.36), p<0.001]$ to be determinant of c-FGF-23 level.

Change in sKL $[\Delta \mathrm{sKL}=-148.6(-237.1$ to -56.8$)$ $\mathrm{pg} / \mathrm{ml}]$ was negatively associated with $\Delta \mathrm{CTX}[\Delta=0.18$ $(0.01-0.27) \mathrm{ng} / \mathrm{ml}$; rho $=-0.4, p=0.03]$ and $\Delta \mathrm{iPTH}$ $(r=-0.6, p=0.001)$.

Level of sKL remained significantly associated with iPTH $(\beta=-0.47[95 \% \mathrm{CI}-0.70$ to $(-0.23)], p<0.001)$ and CTX $[\beta=-0.39(95 \%$ CI -0.68 to $(-0.09))$, $p=0.013$ ] after adjustment for renal function in mixed regression analysis.

\section{Effect of nephrectomy on markers of bone resorption and formation}

Nephrectomy resulted in alterations of bone turnover markers. Serum CTX increased after surgery compared to baseline $(p<0.01$; Fig. $2 \mathrm{a})$, while serum TRAP $5 \mathrm{~b}$ and bALP concentration decreased $(p<0.001 ;$ Fig. $2 \mathrm{~b}$ and $p<0.0001$; Fig. 2c).
Neither $\triangle \mathrm{CTX}, \triangle \mathrm{TRAP} 5 \mathrm{~b}$ nor $\triangle \mathrm{bALP}$ correlated with $\triangle$ eGFR. $\triangle$ CTX evoked by nephrectomy was negatively associated only with changes in sKL concentration (rho $=-0.4, p=0.03$ ) and with alterations of serum phosphate (rho $=0.4, p=0.04$ ). In mixed regression model accounting for time effect, none of aforementioned parameters significantly predicted CTX concentration.

Changes of any evaluated parameters were not associated with bALP ( $\triangle$ bALP) and TRAP 5b ( $\triangle$ TRAP 5 b) alterations.

\section{Discussion}

The aim of this study was to test the hypothesis, whether nephrectomy changes the concentration of c-FGF-23, sKL and affects bone metabolism. Our data show that acute reduction in GFR after nephrectomy does not alter c-FGF-23 concentration in short-term follow-up. It is in line with recent study performed in living kidney donors, which showed rather FGF-23 reduction but not the increase in short term [8]. On the other hand, we are aware that decrease in calcium concentration, observed in our study, might prevent FGF-23 increase, as was shown previously [16]. However, we did not observe any association between calcium and FGF-23 changes. These results are in contrast to data obtained from patients with AKI, in whom elevated FGF-23 levels are observed already after 1-h of AKI onset, with more than tenfold rise at $24 \mathrm{~h}$ [5]. Moreover, in human study it was shown that FGF-23 increase, at the end of cardiac surgery predicted AKI development [6]. The mechanisms underlying augmented FGF-23 levels in patients with AKI are unknown. Our data shed some light on potential mechanism, as it shows there are two possible explanations. Either there must be a threshold of acute GFR decline beyond which FGF-23 production escalates or there is a different factor involved, associated with acute state in the setting of AKI, activating FGF-23 increase.

Currently two assays measuring FGF-23 levels are available. Intact FGF-23 (iFGF-23) assay that detect only a biologically active form and second one, used in our study, an assay measuring both c-terminal fragments and intact form of FGF-23. Thus, if intact form of FGF-23 is elevated then the c-terminal assay also would detect the rise. Of course when c-terminal assay detects elevation in FGF-23 it is difficult to say if there is a rise in iFGF-23 or increase in FGF23 cleavage. Since we did not observe any changes in c-terminal FGF-23 assay, we can hypothesize that in our study neither no increased synthesis, nor degradation occurred. However, without c-FGF-23/iFGF-23 ratio to support our opinion, an alternative explanation is possible. Theoretically, no change in c-terminal FGF-23 measurement could 

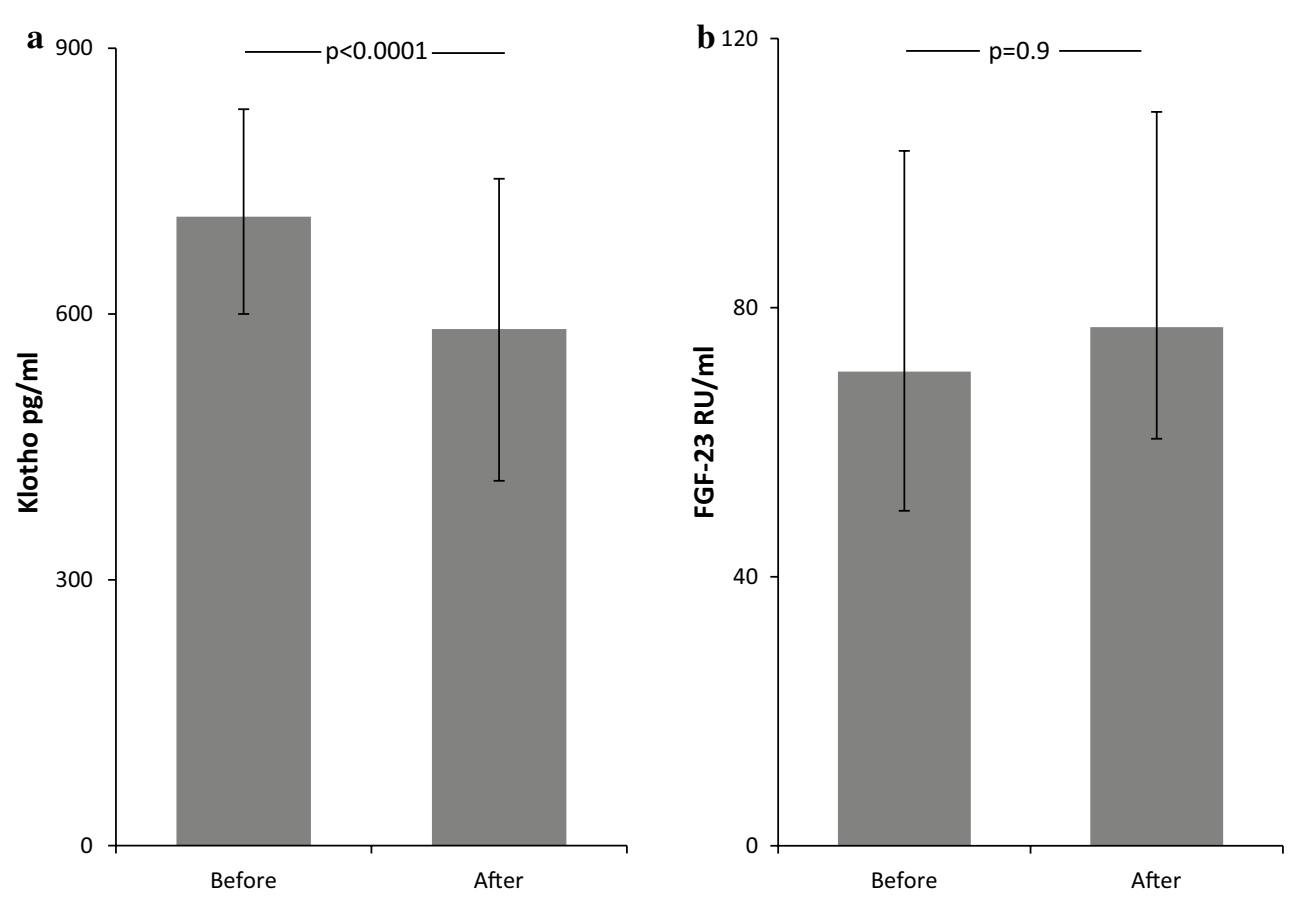

Fig. 1 Impact of nephrectomy on serum levels of a soluble Klotho, b fibroblast growth factor (FGF-23). Data are presented as median and interquartile range
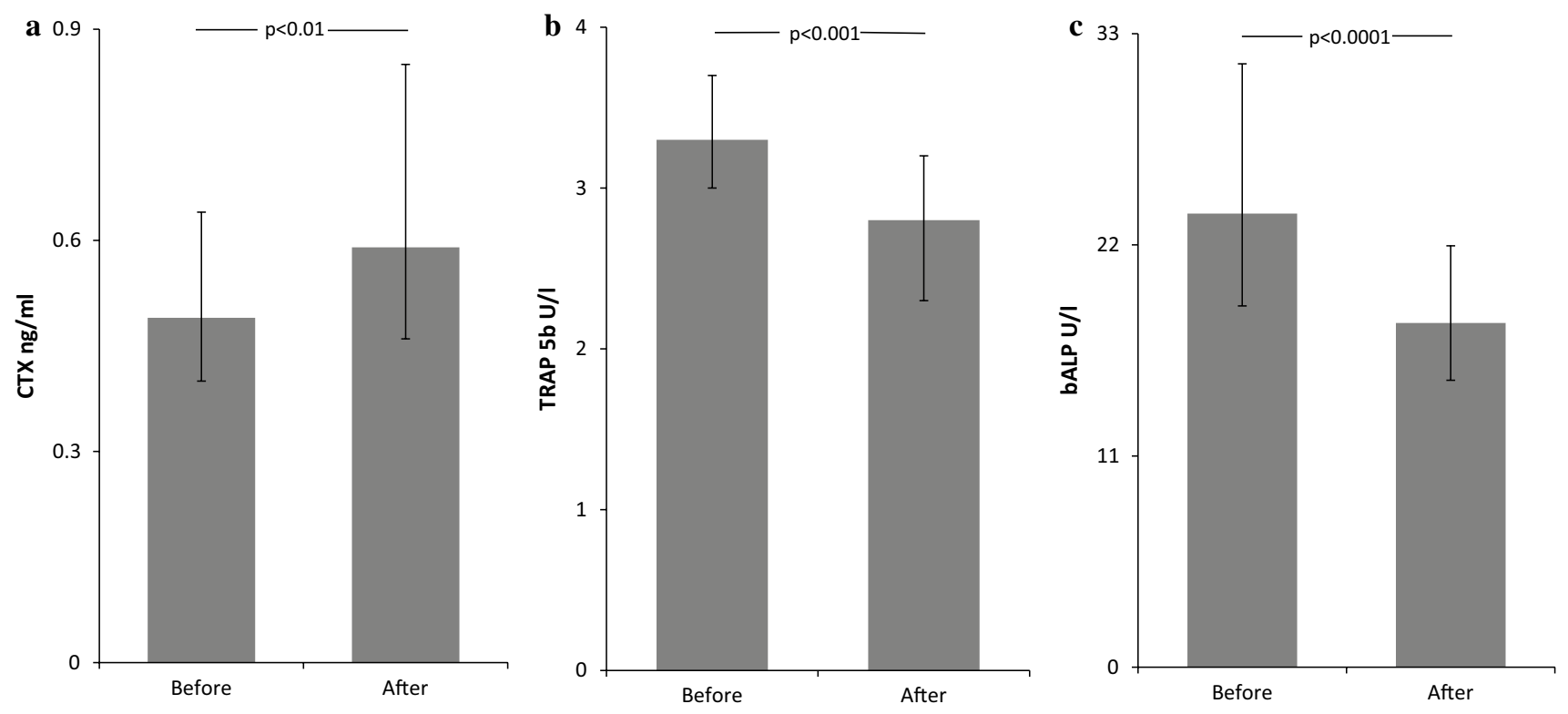

Fig. 2 Impact of nephrectomy on serum levels of a cross-linked C-telopeptide of type 1 collagen (CTX), $\mathbf{b}$ tartrate-resistant acid phosphatase 5b (TRAP 5b) and $\mathbf{c}$ bone-specific alkaline phosphatase (bALP). Data are presented as median and interquartile range

be due to decrease in intact and an increase in c-terminal FGF-23 fragments. Although already published data where both forms of FGF-23 were measured during AKI [5, 6, 17], universally showed increase in c-FGF23 as well as iFGF-23. Thus, we believe that our data add interesting point to the discussion regarding mutual relations between acute GFR decrease and FGF-23 behaviour in different clinical settings. Even though our sample size was small, it provided approximately $80 \%$ power to detect at least $11 \%$ change in c-FGF-23 concentration at $5 \%$ significance 
level, based on power calculations based on two previously published data (for iFGF-23 after nephrectomy [18], and c-FGF-23 after hip replacement procedure [19]).

Whether nephrectomy induces FGF-23 increase with all its negative consequences is especially important for living kidney donors. Data from kidney donors showed that in long-term follow-up after nephrectomy, FGF-23 increases $[9,10,18]$. These results differ from those of our study, although we investigated short-term changes and our study population were patients with urological indications for nephrectomy. We may hypothesize that the increase in FGF-23 occurs at higher GFR decrease than observed in our study or our follow-up was relatively too short to detect changes. A rise in FGF-23 is an effect of GFR decline, and time is essential for those changes to become evident.

Our finding that FGF-23 levels are constant, despite nephrectomy is especially interesting in the context of results obtained by Goebel et al., who reported significant increase in FGF-23 after orthopaedic procedures [19]. It points that rather other stimuli than surgery by itself induces this molecule's production. This hypothesis is in line with data obtained in animal experiment where shamoperated rats FGF-23 levels were stable [20]. Results from ICU patients, where FGF-23 increase was observed despite normal renal function, make the question about factors determining FGF-23 levels even more intriguing [21].

In agreement with previous reports [22], we observed a significant decrease in serum sKL after renal mass reduction, reaffirming the statement that kidneys are the major source of sKL. Study in living kidney donors with longer follow-up demonstrated that sKL increased after the initial postoperative reduction but still was lower than pre-donation [8]. Apart from Klotho's role in ageing and phosphate homoeostasis [23], its soluble form acts as an endocrine protein that exerts pleiotropic actions, including protection of endothelial function by its antioxidant properties, inhibition of vascular calcification, suppression of fibrosis and inflammation $[24,25]$. Reduced sKL may therefore contribute to many complications but how it translates to any patient-oriented measures is still a matter of debate. Even though sKL is discussed as a novel biomarker for progression in CKD [26], there are conflicting data from human studies regarding influence of sKL levels on clinical outcomes, reporting both positive [27] as well as neutral effects [28]. Acute reduction in GFR resulted in derangements in minerals handled by the kidneys, e.g., decreased serum calcium and phosphate levels. The most probable cause of reduction in phosphate concentration was increase in renal losses. Our data showed also increased calcium fractional excretion after nephrectomy. Even though decreased serum calcium is connected to disturbed vitamin D metabolism [29], hypocalcemia may not be specific only to nephrectomy, since hypocalcemia and secondary increase in PTH were observed after different abdominal surgeries [30]. In our opinion, hypercalciuria may be partly caused by sKL reduction, as lack of this molecule diminishes the activity of TRPV5 channels [31] and leads to increased renal calcium excretion although we did not observe significant association between the degree of calciuria and magnitude of sKL reduction.

Another compelling finding of the present study is that an acute decline in GFR, caused by nephrectomy, is associated with the alterations in both markers of bone metabolism: resorption and formation. We have shown in our study the rise in CTX and decrease in bALP and TRAP 5b after nephrectomy. This finding seems to be conflicting as CTX and TRAP $5 \mathrm{~b}$ are both markers of resorption, and we have found their opposite behaviour after surgery. Since CTX tends to accumulate as the renal function declines [32, 33], TRAP $5 b$, which is degraded in the liver, is more accurate in our study population, because kidney function has no effect on circulating TRAP 5 b activity $[34,35]$.

Our study suggests that surgically induced nephron loss leads to decrease in bone turnover, which could disintegrate bone homoeostasis. Although we are aware that due to short-term evaluation in our study, one may speculate that reported changes are rather the effects of the surgery but not renal mass reduction. However, after hip replacement surgery, one week after procedure, no changes in serum calcium, phosphorus, total alkaline phosphatase and urinary phosphorus were reported [36]. Based on current sparse data from human [36] and animal studies [20], it seems that rather nephrectomy but not the surgery induces changes in bone metabolism. Broader impact of the changes initiated by nephrectomy is unclear. Animal work shows that subtotally nephrectomized rats had alterations of the structural and mechanical properties of cortical bone material [37]. Human data reported by Bagrodia et al. [7] revealed the association of radical nephrectomy with higher risk of postoperative osteoporosis and fractures, showing the superiority of partial over radical nephrectomy. On the other hand, in the study of kidney donors, the fracture rate was not significantly higher compared to controls [11], although others reported disturbances in bone metabolism markers [10]. Further studies concerning this matter are needed. If the association between nephrectomy and disturbed bone metabolism is confirmed in a larger study, prevention of changes in bone health might become important concern in management of kidney donors and urological patients.

There are some limitations of this study. We are aware that there is a difficulty in assessment parameters changes after nephrectomy, caused by the possible influence of the fasting before operation, undergoing anaesthesia and intravenous hydration. However, at least with regard to c-FGF23 , recently published study showed that acute volume changes do not impact its measurements [38]. The study 
population consisted of patients with various indications for nephrectomy; therefore, we cannot exclude that the presence of different diseases had an impact on our conclusions. Since our results were uniform and each patient served as their own control, it seems very unlikely although cannot be ruled out. Moreover, our aim was to evaluate the impact of the nephrectomy on FGF-23 and sKL concentrations in patients with preserved renal function; nevertheless, we did not study living kidney donors. Thus, our study's findings might not be relevant to this specific group. Additional study with longer follow-up is needed to confirm that our results are consistent over the time. However, we think that this study makes interesting point in the discussion about FGF23 short-term behaviour after kidney injury, showing that nephrectomy may differ from other types of kidney damage.

The study was not designed to examine patients' outcomes, which does not allow for conclusions regarding causality. Finally, the comparator group and assessing the degree of bone loss by a bone mineral density technique would undoubtedly strengthen our results.

In summary, we present data showing neutral effect of GFR reduction on FGF-23 concentration of patients undergoing nephrectomy due to urological indications. Evoked reduction in renal mass causes decrease in sKL level. Whether it translates to patient-oriented clinical outcomes requires further investigation. Moreover, nephrectomy resulted in derangements in bone turnover markers. These changes may participate in pathogenesis of bone disease after nephrectomy.

Acknowledgements This work was supported by Medical University of Bialystok (research Grants N/ST/ZB/16/001/1154 and N/ST/ ZB/16/002/1154).

\section{Compliance with ethical standards}

Conflict of interest The authors declare that they have no conflict of interest.

Ethical approval All procedures performed in studies involving human participants were in accordance with the ethical standards of the institutional and/or national research committee (Bioethics Committee of The Medical University of Bialystok Approval No. R-I002/124/2014) and with the 1964 Helsinki declaration and its later amendments or comparable ethical standards.

Informed consent Informed consent was obtained from all individual participants included in the study.

Open Access This article is distributed under the terms of the Creative Commons Attribution 4.0 International License (http://creativecommons.org/licenses/by/4.0/), which permits unrestricted use, distribution, and reproduction in any medium, provided you give appropriate credit to the original author(s) and the source, provide a link to the Creative Commons license, and indicate if changes were made.

\section{References}

1. Nitta K, Nagano N, Tsuchiya K (2014) Fibroblast growth factor 23/klotho axis in chronic kidney disease. Nephron Clin Pract 128(1-2):1-10. doi:10.1159/000365787

2. John GB, Cheng CY, Kuro-o M (2011) Role of Klotho in aging, phosphate metabolism, and CKD. Am J Kidney Dis 58(1):127134. doi:10.1053/j.ajkd.2010.12.027

3. Scialla JJ, Xie H, Rahman M, Anderson AH, Isakova T, Ojo A, Zhang X, Nessel L, Hamano T, Grunwald JE, Raj DS, Yang W, He J, Lash JP, Go AS, Kusek JW, Feldman H, Wolf M, Investigators CRICS (2014) Fibroblast growth factor-23 and cardiovascular events in CKD. J Am Soc Nephrol 25(2):349-360. doi:10.1681/asn.2013050465

4. Isakova T, Xie H, Yang W, Xie D, Anderson AH, Scialla J, Wahl P, Gutiérrez OM, Steigerwalt S, He J, Schwartz S, Lo J, Ojo A, Sondheimer J, Hsu CY, Lash J, Leonard M, Kusek JW, Feldman HI, Wolf M, Group CRICS (2011) Fibroblast growth factor 23 and risks of mortality and end-stage renal disease in patients with chronic kidney disease. JAMA 305(23):2432-2439. doi:10.1001/ jama.2011.826

5. Christov M, Waikar SS, Pereira RC, Havasi A, Leaf DE, Goltzman D, Pajevic PD, Wolf M, Jüppner H (2013) Plasma FGF23 levels increase rapidly after acute kidney injury. Kidney Int 84(4):776-785. doi:10.1038/ki.2013.150

6. Leaf DE, Christov M, Jüppner H, Siew E, Ikizler TA, Bian A, Chen G, Sabbisetti VS, Bonventre JV, Cai X, Wolf M, Waikar SS (2016) Fibroblast growth factor 23 levels are elevated and associated with severe acute kidney injury and death following cardiac surgery. Kidney Int 89(4):939-948. doi:10.1016/j. kint.2015.12.035

7. Bagrodia A, Mehrazin R, Bazzi WM, Silberstein J, Malcolm JB, Stroup SP, Raheem O, Wake RW, Kane CJ, Patterson AL, Wan JY, Derweesh IH (2011) Comparison of rates and risk factors for development of osteoporosis and fractures after radical or partial nephrectomy. Urology 78(3):614-619. doi:10.1016/j. urology.2011.02.071

8. Ponte B, Trombetti A, Hadaya K, Ernandez T, Fumeaux D, Iselin C, Martin PY, de Seigneux S (2014) Acute and long term mineral metabolism adaptation in living kidney donors: a prospective study. Bone 62:36-42. doi:10.1016/j.bone.2014.01.020

9. Young A, Hodsman AB, Boudville N, Geddes C, Gill J, Goltzman D, Jassal SV, Klarenbach S, Knoll G, Muirhead N, Prasad GV, Treleaven D, Garg AX, Donor Nephrectomy Outcomes Research Network (2012) Bone and mineral metabolism and fibroblast growth factor 23 levels after kidney donation. Am J Kidney Dis 59(6):761-769. doi:10.1053/j.ajkd.2011.09.019

10. Kasiske BL, Kumar R, Kimmel PL, Pesavento TE, Kalil RS, Kraus ES, Rabb H, Posselt AM, Anderson-Haag TL, Steffes MW, Israni AK, Snyder JJ, Singh RJ, Weir MR (2016) Abnormalities in biomarkers of mineral and bone metabolism in kidney donors. Kidney Int. doi:10.1016/j.kint.2016.05.012

11. Garg AX, Pouget J, Young A, Huang A, Boudville N, Hodsman A, Adachi JD, Leslie WD, Cadarette SM, Lok CE, MonroyCuadros M, Prasad GV, Thomas SM, Naylor K, Treleavan D, Donor Nephrectomy Outcomes Research Network (2012) Fracture risk in living kidney donors: a matched cohort study. Am J Kidney Dis 59(6):770-776. doi:10.1053/j.ajkd.2012.01.013

12. Kakareko K, Rydzewska-Rosolowska A, Brzosko S, Gozdzikiewicz-Lapinska J, Koc-Zorawska E, Samocik P, Kozlowski R, Mysliwiec M, Naumnik B, Hryszko T (2016) Renal handling of sclerostin in response to acute glomerular filtration decline. Horm Metab Res 48(7):457-461. doi:10.1055/s-0042-107791

13. Bijvoet OL, Morgan DB, Fourman P (1969) The assessment of phosphate reabsorption. Clin Chim Acta 26(1):15-24 
14. Walton RJ, Bijvoet OL (1975) Nomogram for derivation of renal threshold phosphate concentration. Lancet 2(7929):309-310

15. Levey AS, Stevens LA, Schmid CH, Zhang YL, Castro AF 3rd, Feldman HI, Kusek JW, Eggers P, Van Lente F, Greene T, Coresh J, Ckd EPI (2009) A new equation to estimate glomerular filtration rate. Ann Intern Med 150(9):604-612

16. Rodriguez-Ortiz ME, Lopez I, Muñoz-Castañeda JR, MartinezMoreno JM, Ramírez AP, Pineda C, Canalejo A, Jaeger P, Aguilera-Tejero E, Rodriguez M, Felsenfeld A, Almaden Y (2012) Calcium deficiency reduces circulating levels of FGF23. J Am Soc Nephrol 23(7):1190-1197. doi:10.1681/asn.2011101006

17. Hanudel MR, Wesseling-Perry K, Gales B, Ramos G, Campbell V, Ethridge K, Scotti M, Elashoff DA, Alejos J, Reemtsen B, Salusky IB (2016) Effects of acute kidney injury and chronic hypoxemia on fibroblast growth factor 23 levels in pediatric cardiac surgery patients. Pediatr Nephrol 31(4):661-669. doi:10.1007/s00467-015-3257-5

18. Westerberg PA, Ljunggren $\mathrm{O}$, Larsson TE, Wadström J, Linde T (2010) Fibroblast growth factor-23 and mineral metabolism after unilateral nephrectomy. Nephrol Dial Transplant 25(12):40684071. doi:10.1093/ndt/gfq288

19. Goebel S, Lienau J, Rammoser U, Seefried L, Wintgens KF, Seufert J, Duda G, Jakob F, Ebert R (2009) FGF23 is a putative marker for bone healing and regeneration. J Orthop Res 27(9):1141-1146. doi:10.1002/jor.20857

20. Mace ML, Gravesen E, Hofman-Bang J, Olgaard K, Lewin E (2015) Key role of the kidney in the regulation of fibroblast growth factor 23. Kidney Int 88(6):1304-1313. doi:10.1038/ ki.2015.231

21. Zhang M, Hsu R, Hsu CY, Kordesch K, Nicasio E, Cortez A, McAlpine I, Brady S, Zhuo H, Kangelaris KN, Stein J, Calfee CS, Liu KD (2011) FGF-23 and PTH levels in patients with acute kidney injury: a cross-sectional case series study. Ann Intensive Care 1(1):21. doi:10.1186/2110-5820-1-21

22. Akimoto $\mathrm{T}$, Kimura $\mathrm{T}$, Watanabe $\mathrm{Y}$, Ishikawa N, Iwazu $\mathrm{Y}$, Saito O, Muto S, Yagisawa T, Kusano E (2013) The impact of nephrectomy and renal transplantation on serum levels of soluble Klotho protein. Transpl Proc 45(1):134-136. doi:10.1016/j. transproceed.2012.07.150

23. Kuro-o M (2013) Klotho, phosphate and FGF-23 in ageing and disturbed mineral metabolism. Nat Rev Nephrol 9(11):650-660. doi:10.1038/nrneph.2013.111

24. Hu MC, Kuro-o M, Moe OW (2012) Secreted klotho and chronic kidney disease. Adv Exp Med Biol 728:126-157. doi:10.1007/978-1-4614-0887-1_9

25. Tan SJ, Smith ER, Hewitson TD, Holt SG, Toussaint ND (2014) The importance of klotho in phosphate metabolism and kidney disease. Nephrology (Carlton) 19(8):439-449. doi:10.1111/ nep. 12268

26. Kim HR, Nam BY, Kim DW, Kang MW, Han JH, Lee MJ, Shin DH, Doh FM, Koo HM, Ko KI, Kim CH, Oh HJ, Yoo TH, Kang SW, Han DS, Han SH (2013) Circulating $\alpha$-klotho levels in CKD and relationship to progression. Am J Kidney Dis 61(6):899909. doi:10.1053/j.ajkd.2013.01.024
27. Nowak A, Friedrich B, Artunc F, Serra AL, Breidthardt T, Twerenbold R, Peter M, Mueller C (2014) Prognostic value and link to atrial fibrillation of soluble Klotho and FGF23 in hemodialysis patients. PLoS ONE 9(7):e100688. doi:10.1371/journal. pone. 0100688

28. Seiler S, Rogacev KS, Roth HJ, Shafein P, Emrich I, Neuhaus S, Floege J, Fliser D, Heine GH (2014) Associations of FGF23 and sKlotho with cardiovascular outcomes among patients with CKD stages 2-4. Clin J Am Soc Nephrol 9(6):1049-1058. doi:10.2215/cjn.07870713

29. Saha H, Mustonen J, Pietilä K, Pasternack A (1993) Metabolism of calcium and vitamin D3 in patients with acute tubulointerstitial nephritis: a study of 41 patients with nephropathia epidemica. Nephron 63(2):159-163

30. Lepage R, Légaré G, Racicot C, Brossard JH, Lapointe R, Dagenais M, D'Amour P (1999) Hypocalcemia induced during major and minor abdominal surgery in humans. J Clin Endocrinol Metab 84(8):2654-2658. doi:10.1210/jcem.84.8.5889

31. Chang Q, Hoefs S, van der Kemp AW, Topala CN, Bindels RJ, Hoenderop JG (2005) The beta-glucuronidase klotho hydrolyzes and activates the TRPV5 channel. Science 310(5747):490-493. doi:10.1126/science. 1114245

32. Ureña P, De Vernejoul MC (1999) Circulating biochemical markers of bone remodeling in uremic patients. Kidney Int 55(6):2141-2156. doi:10.1046/j.1523-1755.1999.00461.x

33. Magnusson P, Sharp CA, Magnusson M, Risteli J, Davie MW, Larsson L (2001) Effect of chronic renal failure on bone turnover and bone alkaline phosphatase isoforms. Kidney Int 60(1):257265. doi:10.1046/j.1523-1755.2001.00794.x

34. Bieglmayer C, Dimai HP, Gasser RW, Kudlacek S, ObermayerPietsch B, Woloszczuk W, Zwettler E, Griesmacher A (2012) Biomarkers of bone turnover in diagnosis and therapy of osteoporosis: a consensus advice from an Austrian working group. Wien Med Wochenschr 162(21-22):464-477. doi:10.1007/ s10354-012-0133-9

35. Shidara K, Inaba M, Okuno S, Yamada S, Kumeda Y, Imanishi Y, Yamakawa T, Ishimura E, Nishizawa Y (2008) Serum levels of TRAP5b, a new bone resorption marker unaffected by renal dysfunction, as a useful marker of cortical bone loss in hemodialysis patients. Calcif Tissue Int 82(4):278-287. doi:10.1007/ s00223-008-9127-4

36. Tsakalakos N, Magiasis B, Tsekoura M, Lyritis G (1993) The effect of short-term calcitonin administration on biochemical bone markers in patients with acute immobilization following hip fracture. Osteoporos Int 3(6):337-340

37. Nazarian A, Cory E, Müller R, Snyder BD (2009) Shortcomings of DXA to assess changes in bone tissue density and microstructure induced by metabolic bone diseases in rat models. Osteoporos Int 20(1):123-132. doi:10.1007/s00198-008-0632-0

38. Humalda JK, Seiler-Muler S, Kwakernaak AJ, Vervloet MG, Navis G, Fliser D, Heine GH, de Borst MH (2016) Response of fibroblast growth factor 23 to volume interventions in arterial hypertension and diabetic nephropathy. Medicine (Baltimore) 95(46):e5003. doi:10.1097/md.0000000000005003 